\title{
Employment status and work-related difficulties in stomach cancer survivors compared with the general population
}

\author{
MK Lee', KM Lee', J-M Bae', S Kim², Y-W Kim', KW Ryu', JH Lee', J-H Noh², T-S Sohn², S-K Hong ${ }^{2}$ and \\ YH Yun ${ }^{*, 1}$
}

'Research Institute and Hospital, National Cancer Center, 809 Madu dong, Ilsan gu, Goyang si, Gyeonggi do 4II-769, Korea; ${ }^{2}$ Department of Surgery, Samsung Medical Center, Sungkyunkwan University, School of Medicine, Seoul, Korea

\begin{abstract}
Little was known about work situation and work-related difficulties, including housework after stomach cancer diagnosis. We aimed to compare employment status and work-related difficulties between stomach cancer survivors and the general population. We enrolled 408 stomach cancer survivors from two hospitals 28 months after diagnosis and 994 representative volunteers from the general population from 15 geographic districts. Working was defined as being employed (including self-employed) and nonworking as being retired or a homemaker. Nonworking was significantly higher among stomach cancer survivors (46.6\%) than in the general population (36.5\%). Compared with the general population, the survivors had more fatigue in performing both housework (adjusted odds ratio $(\mathrm{aOR})=2.08 ; 95 \%$ confidence interval $(95 \% \mathrm{Cl})=1.0 \mathrm{I}-4.29)$ and gainful work $(\mathrm{aOR}=4.02 ; 2.55-6.33)$. More cancer survivors had reduced working hours $(\mathrm{aOR}=1.42 ; 95 \% \mathrm{Cl}=4.60-28.35)$ and reduced work-related ability $(\mathrm{aOR}=6.1 \mathrm{I} ; 95 \%$ $\mathrm{Cl}=3.64-10.27$ ) than did the general population. The association of nonworking with older age and being female was significantly more positive for survivors than for the general population. Among survivors, poorer Eastern Cooperation Oncology Group Performance Status and receiving total gastrectomy were positively associated with nonworking. Stomach cancer survivors experienced more difficulties in both housework and gainful employment than did the general population. Our findings on stomach cancer survivors' work-related difficulties and the predictors of nonworking will help physicians guide patients towards more realistic postsurgical employment plans.

British Journal of Cancer (2008) 98, 708-715. doi:I0.1038/sj.bjc.6604236 www.bjcancer.com

Published online 19 February 2008

(C) 2008 Cancer Research UK
\end{abstract}

Keywords: employment status; work; stomach cancer survivor; general population

Stomach cancer is the fourth most common malignancy in the world, with an estimated 870000 new cases reported each year (Stewart et al, 2003). Over the past 20 years, early detection and treatment improvements have led to an increased number of longterm stomach cancer survivors (Roukos, 1999).

Returning to work and performing housework after recovering from cancer is important to the survivors' family and social roles as well as to their finances. Cancer survivors may return to the work they did before diagnosis, but they may experience new physical limitations as a result of the disease and its treatment (Hewitt et al, 2003). Many studies have assessed the employment status of cancer survivors (Maunsell et al, 2004; Yabroff et al, 2004; Bednarek and Bradley, 2005; Bradley et al, 2005; Drolet et al, 2005; Short et al, 2005; Bouknight et al, 2006), but only four of them included comparison groups (Maunsell et al, 2004; Yabroff et al, 2004; Bradley et al, 2005; Drolet et al, 2005), which are crucial to detecting cancer-specific effects. Furthermore, the majority of studies focused on breast (Maunsell et al 2004; Drolet et al, 2005;

*Correspondence: Dr YH Yun; E-mail: lawyun08@ncc.re.kr

The poster of this article was presented (June 2) at the 43rd Annual Meeting of the American Society of Clinical Oncology, Chicago, IL, USA, I-5, June 2007.

Received 14 August 2007; revised 7 January 2008; accepted 9 January 2008; published online 19 February 2008
Bouknight et al, 2006) or heterogeneous types of cancer (Bradley and Bednarek, 2002a; Yabroff et al, 2004; Bednarek and Bradley, 2005; Short et al, 2005) and did not consider the survivors' ability to do housework. Little is known about the employment status and work-related difficulties associated with stomach cancer. The initial complications of its treatment, such as eating restrictions, weight loss, fatigue, and anxiety (Vickery et al, 2001; Bae et al, 2006), may diminish the long-term health-related quality of life. The effect of stomach cancer treatment on long-term health-related quality of life can limit or destroy the ability to work. To investigate this issue, we compared stomach cancer survivors' employment status, workplace-related difficulties, houseworkrelated difficulties, and correlates of not working with those of the general population.

\section{MATERIALS AND METHODS}

\section{Study population}

Survivors We identified the patients for this cross-sectional study through the stomach (ICD code, C16) surgery database at the National Cancer Center and the Seoul Samsung Medical Center in Korea. Like the patients, representative of all hospitals in Korea, the study sample from the two hospitals resided in 15 geographic districts spread across the country. We collected information on 
the stage, type of surgery, time since surgery, history of cancer therapy, extent of lymphadenectomy, and recurrence from the hospital cancer registries. Eligibility required a diagnosis of stage I-III stomach cancer during 2001 or 2002 and being physically and mentally fit to fill out the questionnaire. Patients were excluded if they had a prior history of another cancer, could not speak Korean, or were $<18$ years old. We invited eligible patients to participate in the study by telephone, and those who agreed to participate were sent the questionnaire with consent forms and a postage-paid return envelope. Subjects who did not return the questionnaire within a month received a reminder card and a phone call by a staff member who explained the purpose of the study and requested participation. Interested subjects were asked to sign the informed consent form and to complete and return the questionnaire. Subjects who did not want to participate were asked their reasons. We reviewed the patient-reported questionnaires to check for missing or incomplete information and to confirm consistency between the clinical database and the self-reported data. When we found inconsistencies, we resolved them by telephonic communication with the family. We reflected the final confirmation as survivors' data. Hospital records yielded 887 patients who had undergone curative surgery for stomach cancer during 2001 or 2002. Of those, 32 who had a prior history of another cancer or could not speak Korean, or who were $<18$ years old were excluded. Of the 855 potentially eligible remaining patients, 83 had died and 81 were not contacted. We were able to contact 691 patients by telephone. Of those, 97 refused to participate and 165 did not return the questionnaire. The most frequent reasons survivors gave for refusing to participate or to return the questionnaire were as follows (i) they thought completing the questionnaire was too time-consuming, (ii) they had no help in writing, or (iii) they regarded it as inconvenient or a violation of privacy.

Of the remaining 429 patients, 18 were excluded because they did not complete the questionnaire and three were excluded because they experienced a recurrence of cancer. That left 408 patients in the final sample (response rate, 59.0\%).

General population In each district, the survey was conducted in age and sex strata according to the guidelines of the 2000 Korean census. We selected villages and streets using the probability proportional to size (PPS) technique, which is widely used and is the recommended method for obtaining a representative national sample (Levy and Lemeshow, 1991). Probability proportional to size technique considers the size of individual groups and corrects for differences in the probability of larger and smaller groups being sampled. Eligibility criteria included being physically and mentally fit to fill out the questionnaire or communicate with the interviewer and being $\geqslant 18$ years old. The representative sample $\geqslant 18$ years old consisted of 2447 persons. The interviewers visited each person at home or in the workplace, evaluated the eligibility, and explained the purpose of the study to the eligible person. Of 2447 potentially eligible persons, 1447 refused to participate or did not complete the survey. The most frequent reasons people gave for refusing to participate were that they felt too busy to complete the questionnaire $(n=734)$, that the survey was inconvenient $(n=356)$, that they did not want to provide personal information ( $n=156)$, or others. One thousand of the eligible persons who agreed to participate completed the self-reported questionnaire in the presence of an interviewer who was there to explain the purpose of the study, but like the survivors, they completed the questionnaire for themselves without the interviewer's assistance. Of those who completed the survey, six had a history of cancer and were excluded. We enrolled 994 members of the eligible general population for the comparison group. All participants provided written informed consent. Although the response rate in this study (41\%) was low, the sample appeared to be representative of the general population because the distribution of age and sex was similar to that of the 2000 Korean census (Yun et al, 2007).

\section{Study variables}

We used a questionnaire to collect information on the employment status and socio-demographic characteristics of stomach cancer survivors and the general population. 'Working' was defined as being employed or self-employed and 'nonworking' as being retired or a homemaker. If participants were currently working, they were asked what kind of work-related difficulties they were having. The question included the following five multiple-choice items: (1) reduced working hours, (2) lessened work-related ability than before cancer diagnosis, (3) easily fatigued and exhausted, (4) reduced opportunity for promotion, and (5) decreased wages. If the items were not applicable, participants were asked to write in their work-related difficulties. If they were homemakers, they were asked what kind of housework-related difficulties they were having. The question included the following three multiple-choice items: (1) physically limited, (2) easily fatigued and exhausted but not physically limited, (3) emotionally distressed (such as feeling depressed or anxious). If the choice was not applicable, participants were asked to write in their housework-related difficulties. We did not specifically measure physical limitations as an item for work-related difficulties but used 'reduced working hours' and 'lessened work-related ability than before' as measures of work-related difficulties following physical limitations. If they were currently not working (except for homemakers), they were asked why they were not working. The question included the same three multiple-choice items used for homemakers (above). If the three multiple-choice items were not applicable, participants were asked to write in the reason for not working. We based most of the work-related questions on earlier studies (Maunsell et al, 2004; Yabroff et al, 2004; Bradley et al, 2005; Drolet et al, 2005; Short et al, 2005). Feasibility and comprehensibility of the full survey instrument - including work- and housework-related difficulties, reasons for unemployment, and socio-demographic and clinical characteristics - were pretested with 15 stomach cancer survivors in an outpatient clinic of the Korean National Cancer Center. Pretesting did not change the survey instrument, but no independent validation study was done.

\section{Statistical analysis}

Differences of observed characteristics in the cancer survivors and general population can lead to biased estimates of the effect of cancer on employment. Therefore, we used propensity scores to balance the observable characteristics of the treatment (in our case, stomach cancer) and minimise bias in the selection of cases $v s$ referent (Rosenbaum and Rubin, 1983). For an individual, propensity score is the probability of being treated (or, in this case, having stomach cancer) on the basis of observed characteristics (age, sex, education, marital status, religion, health cost financing, monthly household income, number of comorbidities, and number of family members), but score adjustment did not correct for differences between survivors and controls in unobserved characteristics. The propensity score is the estimated logistic regression model. Missing income data $(n=74)$ were estimated by simple imputation via multivariate regression imputation. All estimates were robust as to whether we imputed the missing income data or excluded the imputed income data from the analysis. All statistical tests were two-sided. We used $t$-tests for continuous variables and $\chi^{2}$ tests for categorical variables in univariate analyses. We included variables with $P<0.05$ in univariate analyses in the multivariate logistic regression model, with a stepwise selection method.

\section{Ethics}

The Institutional Review Boards of National Cancer Center and Samsung Medical Center approved the study. 


\section{RESULTS}

\section{Patient characteristics}

The proportion of homemakers among the survivors $(22.3 \%)$ and in the general population sample $(22.7 \%)$ before propensity score adjustment did not differ significantly. Stomach cancer survivors differed significantly from the general population in several sociodemographic characteristics at baseline, but not after adjustment for propensity score (Table 1).

\section{Employment status of cancer survivors and general population}

Table 2 shows survivors' employment status at the time of diagnosis and at 28 months (range, 21-36 months) after diagnosis compared with the general population's employment status. The proportion working at the time of diagnosis was similar for stomach cancer survivors $(65.9 \%)$ and the general population $(63.5 \%)$. After diagnosis and treatment, however, the percentage of nonworking among survivors $(46.6 \%)$ was higher than that among

Table I Sociodemographic characteristics of stomach cancer survivors and general population before and after propensity score adjustment

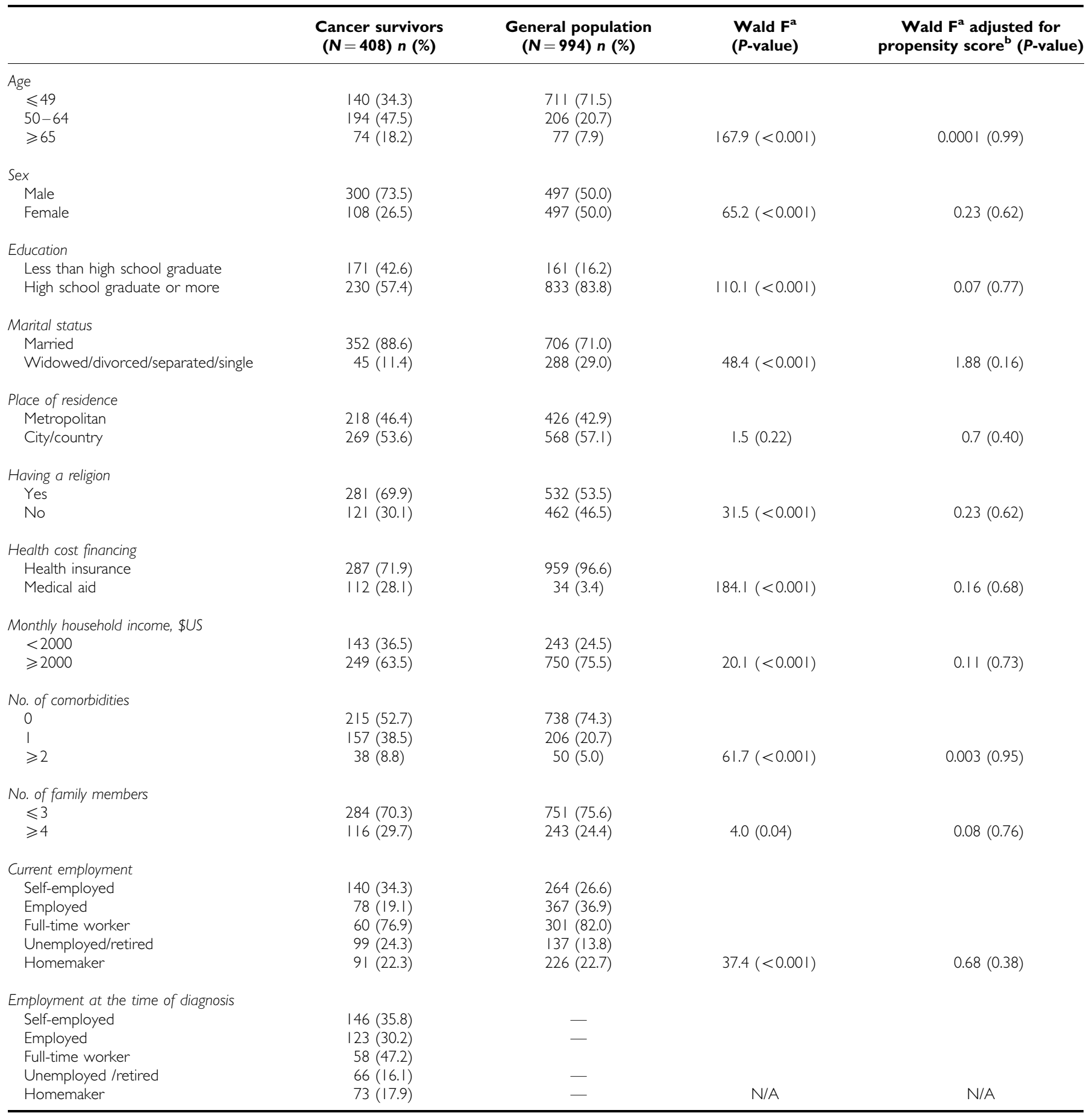

Abbreviations: $N / A=$ not applicable. ${ }^{\mathrm{a}} \mathrm{F}$ statistics based on Wald $\chi^{2}$. ${ }^{\mathrm{b}}$ The propensity score summarizes the differences in observable characteristics between cancer survivors and general population, that is, age, sex, education, marital status, religion, monthly household income, health cost financing, number of family members, and number of comorbidities. 
Table 2 Model-based adjusted odds ratio for not working for stomach cancer survivors (I) compared with the general population and (2) currently compared with the time of diagnosis

\begin{tabular}{|c|c|c|c|c|c|}
\hline & Working n (\%) & Not working $n(\%)$ & aOR $(95 \% \mathrm{Cl})^{\mathrm{a}}$ & aOR $(95 \% \mathrm{Cl})^{b}$ & $\operatorname{aOR}(95 \% \mathrm{CI})^{\mathrm{c}}$ \\
\hline \multicolumn{6}{|l|}{ General population $(n=994)$} \\
\hline Current employment status & $631(63.5)$ & $363(36.5)$ & I (referent) & - & I (referent) \\
\hline \multicolumn{6}{|l|}{ Cancer sunvivors $(n=408)$} \\
\hline Employment status at diagnosis & $269(65.9)$ & $139(34.1)$ & $0.75(0.53-1.08)$ & I (referent) & - \\
\hline Current employment status & $218(53.4)$ & $190(46.6)$ & - & $2.26(1.61-3.15)$ & $1.75(1.28-2.53)$ \\
\hline
\end{tabular}

Abbreviations: $\mathrm{aOR}=$ adjusted odds ratio. ${ }^{\mathrm{a}} \mathrm{aOR}$ for not working at the time of diagnosis for cancer survivors compared with current employment status in the general population, adjusted for age, sex, education, marital status, religion, monthly household income, type of health cost financing, number of family members, number of comorbidities, and propensity score. ${ }^{b} \mathrm{aOR}$ for cancer survivors of currently not working compared with their employment status at the time of diagnosis, adjusted for age. $\mathrm{c}^{\mathrm{a}} \mathrm{OR}$ for currently not working for cancer survivors vs the general population, adjusted for age, sex, education, marital status, religion, monthly household income, type of health cost financing, number of family members, number of comorbidities, and propensity score.

Table 3 The comparison ${ }^{a}$ of work-related difficulties between the stomach cancer survivors and the general population

\begin{tabular}{|c|c|c|}
\hline \multicolumn{3}{|l|}{ Work-related difficulties experienced by worker } \\
\hline Reduced working hours, $n$ (\%) & $13(2.1)$ & $22(13.6)$ \\
\hline Lessened work-related ability than before ${ }^{\mathrm{b}} \mathrm{n}(\%)$ & $67(10.6)$ & $60(37.0)$ \\
\hline $\mathrm{aOR}(95 \% \mathrm{Cl})$ & I (referent) & $6.11(3.64-10.27)$ \\
\hline Easily fatigued and exhausted, $n$ (\%) & $|4|(22.4)$ & $81(50.0)$ \\
\hline $\mathrm{aOR}(95 \% \mathrm{Cl})$ & I (referent) & $4.02(2.55-6.33)$ \\
\hline Decreased wages, $n(\%)$ & $253(40.1)$ & $50(30.9)$ \\
\hline $\mathrm{aOR}(95 \% \mathrm{Cl})$ & I (referent) & $0.71(0.45-1.10)$ \\
\hline \multirow{4}{*}{$\begin{array}{l}\text { Housework-related difficulties experienced by home maker } \\
\text { Emotional distress (depression or anxiety), n (\%) } \\
\text { aOR }(95 \% \mathrm{Cl}) \\
\text { Easily fatigued and exhausted but no physical limitation, n (\%) } \\
\text { aOR }(95 \% \mathrm{Cl}) \\
\text { Physical limitations, } n(\%) \\
\text { aOR }(95 \% \mathrm{Cl})\end{array}$} & $n=226$ & $n=91$ \\
\hline & $9(4.0)$ & $10(12.7)$ \\
\hline & I (referent) & $5.69(1.65-19.55)$ \\
\hline & $|3|(58.0)$ & $58(73.4)$ \\
\hline \multirow{5}{*}{$\begin{array}{l}\text { Reasons for non-working } \\
\text { Physical limitations, } n(\%) \\
\text { aOR }(95 \% \mathrm{Cl}) \\
\text { Easily fatigued and exhausted but no physical limitation, n (\%) } \\
\text { aOR }(95 \% \mathrm{Cl})\end{array}$} & $n=363$ & $n=190$ \\
\hline & $7(1.9)$ & $40(21.1)$ \\
\hline & I (referent) & $7.68(3.64-10.27)$ \\
\hline & $16(4.4)$ & $24(12.6)$ \\
\hline & I (referent) & $1.84(0.70-4.88)$ \\
\hline \multirow{3}{*}{$\begin{array}{l}\text { Emotional distress (depression or anxiety), } n(\%) \\
\quad \text { OOR }(95 \% \mathrm{Cl})\end{array}$} & $0(0.0)$ & $2(1.1)$ \\
\hline & I (referent) & N/A \\
\hline & $28(7.7)$ & $29(15.3)$ \\
\hline $\mathrm{aOR}(95 \% \mathrm{Cl})$ & I (referent) & $1.75(0.34-3.68)$ \\
\hline
\end{tabular}

Abbreviations: $\mathrm{aOR}=$ adjusted odds ratio; $\mathrm{Cl}=$ confidence interval; $\mathrm{N} / \mathrm{A}=$ Not Available. ${ }^{\mathrm{a}} \mathrm{aOR}$ for general population vs cancer survivors, adjusted for age, sex, education, marital status, religion, monthly household income, type of health cost financing, number of family members, number of comorbidities, and propensity score. ${ }^{\text {b}}$ The item was 'Lessened work-related ability than before cancer diagnosis' for survivors and 'Lessened work-related ability than before; for the general population. 'Etc includes 'not wanting to work' and 'not having been employed since the previous time'.

the general population (36.5\%) (adjusted odds ratio $(\mathrm{aOR})=1.75$, $95 \%$ confidence interval $(\mathrm{CI})=1.28-2.53)$. In the stratified analyses by age and sex, the proportion of cancer survivors working was currently significantly lower than at the time of diagnosis (respectively, male, 65.9 vs $85.8 \%$; female, 18.3 vs $34.8 \%$; $<50$-year-old, 64.6 vs $77.6 \%$; 50 - to 64 -year-old, 57.6 vs $73.4 \%$; $\geqslant 65$-year-old, 25.0 vs 53.1\%. $P<0.05$ for all).

Physical limitation as the reason for nonworking was significantly higher for survivors than for the general population $(\mathrm{aOR}=7.68 ; 95 \% \mathrm{CI}=3.64-10.27)$.

\section{Work- and housework-related difficulties}

Table 3 shows work- and housework-related difficulties for cancer survivors and the general population. Compared with the general population, cancer survivors had a greater risk of reduced working hours $(\mathrm{aOR}=11.42 ; 95 \% \mathrm{CI}=4.60-28.35)$ and workrelated disability $(\mathrm{aOR}=6.11 ; 95 \% \mathrm{CI}=3.64-10.27)$, and they were more easily fatigued and exhausted in the workplace $(\mathrm{aOR}=4.02 ; 95 \% \mathrm{CI}=2.55-6.33)$. Those doing housework had more emotional distress $(\mathrm{aOR}=5.69 ; 95 \% \mathrm{CI}=1.65-19.55)$ and were also more easily fatigued and exhausted $(\mathrm{aOR}=2.08 ; 95 \%$ $\mathrm{CI}=1.01-4.29)$.

\section{Associated factors with employment status in the survivors and general population}

Table 4 shows the results of univariate analyses. In cancer survivors, age, sex, educational level, marital status, monthly household income, number of comorbidities, and number of 
family members were associated with employment status. In the general population, age, sex, educational level, marital status, having a religion, monthly household income, and number of comorbidities were associated with employment status.

Table 5 shows the results of multivariate logistic regression. In cancer survivors, being older $(\mathrm{aOR}=14.17,95 \% \mathrm{CI}=5.25-38.23)$ or female $(\mathrm{aOR}=16.83,95 \% \mathrm{CI}=8.30-34.11)$, having had a total gastrectomy $(\mathrm{aOR}=2.44,95 \% \mathrm{CI}=1.26-4.17)$, and having a poor ECOG performance status $(\mathrm{aOR}=2.12,95 \% \mathrm{CI}=1.19-3.78)$ were related to an increased probability of not being employed. In the general population, being older $(\mathrm{aOR}=6.02,95 \% \mathrm{CI}=3.26-$ 10.99), female $(\mathrm{aOR}=5.43,95 \% \mathrm{CI}=3.99-7.32)$, or unmarried $(\mathrm{aOR}=2.00,95 \% \mathrm{CI}=1.44-2.79)$ and having two or more comorbidities $(\mathrm{aOR}=2.91,95 \% \mathrm{CI}=1.42-6.09)$ were related to an increased probability of not being employed. When we performed these analyses without adjusting for propensity score, the results were similar but the statistical power was less (data not shown).

Table 4 The univariate results of relationship between employment status in stomach cancer survivors and general population

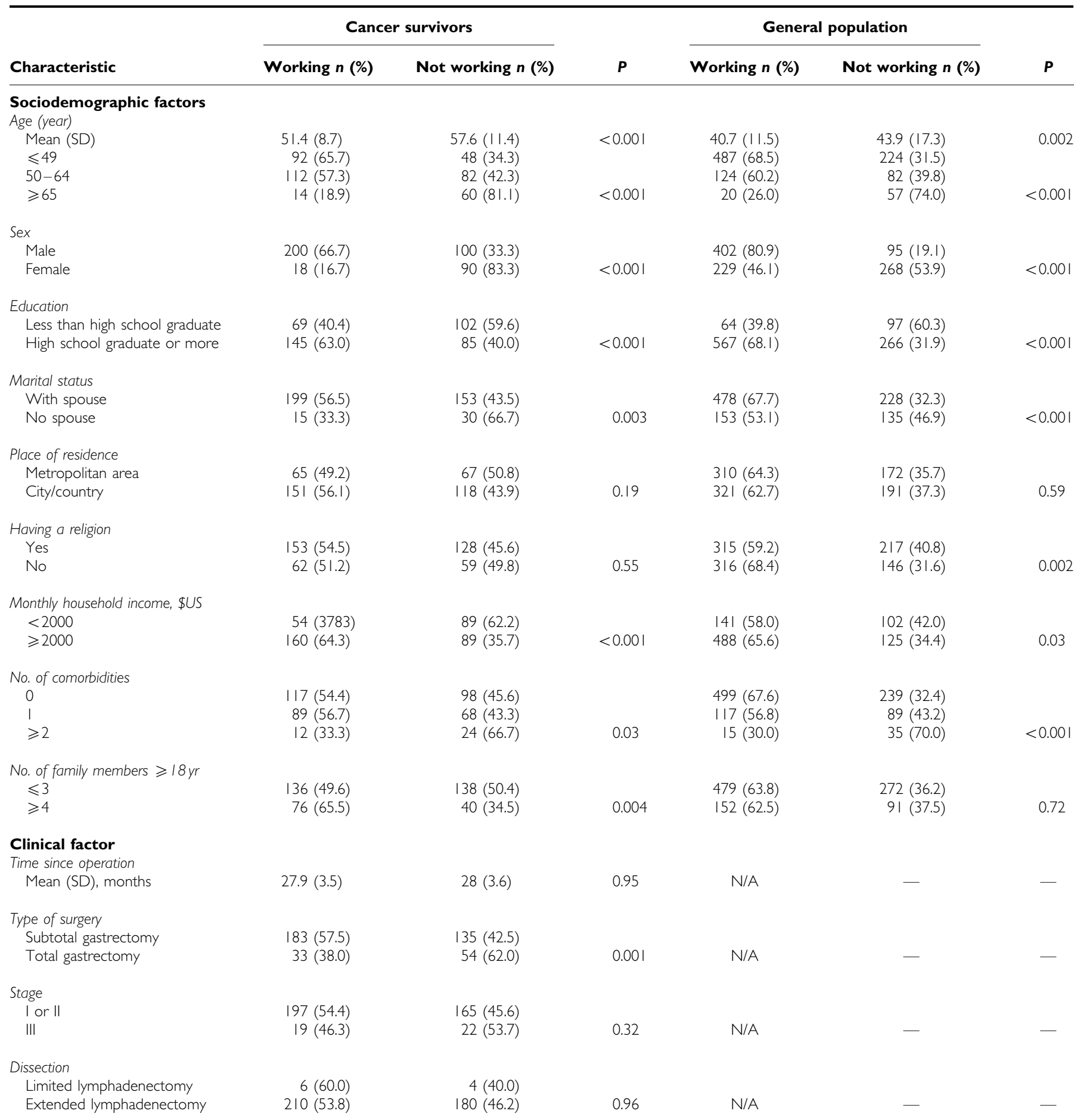


Table 4 (Continued)

\begin{tabular}{|c|c|c|c|c|c|c|}
\hline \multirow[b]{2}{*}{ Characteristic } & \multicolumn{2}{|c|}{ Cancer survivors } & \multirow[b]{2}{*}{$P$} & \multicolumn{2}{|c|}{ General population } & \multirow[b]{2}{*}{$P$} \\
\hline & Working n (\%) & Not working n (\%) & & Working n (\%) & Not working n (\%) & \\
\hline \multicolumn{7}{|l|}{ Received radiation } \\
\hline Yes & $26(54.2)$ & $22(45.8)$ & & & & \\
\hline No & $|8|(52.9)$ & $161(47.1)$ & 0.87 & N/A & - & - \\
\hline \multicolumn{7}{|c|}{ Received chemotherapy } \\
\hline No & $157(55.3)$ & $127(44.7)$ & 0.07 & $N / A$ & - & - \\
\hline \multicolumn{7}{|l|}{ ECOG PS ${ }^{\mathrm{a}}$} \\
\hline I & $156(63.7)$ & $89(36.3)$ & & & & \\
\hline $2 \sim 4$ & $53(37.1)$ & $90(62.9)$ & $<0.001$ & $\mathrm{~N} / \mathrm{A}$ & - & - \\
\hline \multicolumn{7}{|c|}{ Time since operation, months } \\
\hline
\end{tabular}

Table 5 Model-based adjusted odds ratio of not working by logistic regression analysis with the stepwise method in cancer survivors and general population

\begin{tabular}{|c|c|c|c|c|}
\hline \multirow[b]{2}{*}{ Characteristic } & \multicolumn{2}{|c|}{ Cancer survivors $(N=408)$} & \multicolumn{2}{|c|}{ General population $(N=994)$} \\
\hline & aOR for not working $(95 \% \mathrm{Cl})$ & $\mathbf{P}$ & aOR for not working $(95 \% \mathrm{Cl})$ & $P$ \\
\hline$\leqslant 49$ & I (referent) & & I (referent) & \\
\hline $50-64$ & $2.5 \mid(|.28-4.9|)$ & 0.007 & $1.50(1.02-2.14)$ & 0.04 \\
\hline$\geqslant 65$ & $14.17(5.25-38.23)$ & $<0.001$ & $6.02(3.26-10.99)$ & $<0.001$ \\
\hline \multicolumn{5}{|l|}{ Sex } \\
\hline \multicolumn{5}{|l|}{ Marital status } \\
\hline With spouse & I (referent) & & I (referent) & \\
\hline No spouse & $1.88(0.57-6.23)$ & 0.230 & $2.00(1.44-2.79)$ & $<0.001$ \\
\hline \multicolumn{5}{|l|}{ No. of comorbidities } \\
\hline 0 & I (referent) & & I (referent) & \\
\hline । & $0.64(0.21-1.96)$ & 0.328 & $0.83(0.40-1.74)$ & 0.617 \\
\hline \multicolumn{5}{|l|}{ Type of surgery } \\
\hline Total gastrectomy & $2.44(1.26-4.17)$ & 0.007 & $N / A$ & \\
\hline \multicolumn{5}{|l|}{ ECOG PS } \\
\hline I & I (referent) & & & \\
\hline $2 \sim 4$ & $2.12(1.19-3.78)$ & 0.01 & $N / A$ & - \\
\hline
\end{tabular}

Abbreviations: $(\mathrm{aOR})=$ Model-based adjusted odds ratios, ECOG PS = Eastern Cooperation Oncology Group Performance Status; N/A = not applicable. ${ }^{a}$ Model-based adjusted odds ratios (aOR) are from a series of logistic regression models with stepwise method whose covariates were statistically significant $(P<0.05)$ in univariate analyses (Table 4).

\section{DISCUSSION}

Most previous studies of cancer survivors' employment status focused on breast or prostate cancer, which are common in Western Europe. To our knowledge, this is the first study to examine work- and housework-related difficulties and the correlates of employment status for stomach cancer survivors $v \mathrm{~s}$ the general population. Although comparisons with previous studies may not be appropriate because of differences in length of follow-up, health care access, and disability laws, our finding that nonworking was $10 \%$ higher in stomach cancer survivors was similar to the findings of studies of breast cancer survivors and prostate cancer (Bradley et al, 2002b; Bradley et al, 2005; Drolet et al, 2005).

Our findings that stomach cancer survivors had difficulties in performing work due to increased fatigue and reduced workcapacity were also in agreement with findings from other studies (Stewart et al, 2001; Bradley and Bednarek, 2002a, Short et al, 2005). However, our findings were specific for stomach cancer survivors because we focused on comparing cancer survivors with 
the general population. Fatigue was a common problem in performing both housework and gainful work. Thus, even homemakers who did not work competitively or have assigned responsibilities experienced more fatigue than their counterparts in the general population. Because survivors may not be able to perform their normal home chores (Collins et al, 2004), their family role could change. This has been studied before among women with cancer (Collins et al, 2004; Serin et al, 2005). concluded that fatigue and anxiety were the most frequent problems for breast and gynaecological cancer patients, and those problems made housework more difficult (Zakowski et al, 2003). There were no reports of emotional distress being a work-related difficulty among workers and only two reports of it being the reason for current unemployment among nonworkers. Homemakers diagnosed with stomach cancer, however, might be more depressed than homemakers in the general population. We discuss the finding that having cancer and being a homemaker and balancing these two roles may be more difficult for stomach cancer survivors than for the general population. Families with a cancer patient may need to provide an emotional support system for them.

Our finding that older age and being female were common correlates of postcancer work cessation also agreed with previous results (Lash and Silliman, 2000; Spelten et al, 2003; Drolet et al, 2005), but we showed that this was the case relative to the general population. The correlation with older age may reflect the fact that the cancer occurred at a time of life when patients may have already been thinking about retirement or working less (Lash and Silliman, 2000; Drolet et al, 2005) and that greater physical limitations increased the tendency to stop working.

Our observation that women were less likely than men to work after cancer is in keeping with a previous study showing that women had more cancer-related disabilities than men (Short et al, 2005). Female stomach cancer survivors might find work difficult and attribute their work problems, or their personal decision to work less, to their disease (Yabroff et al, 2004). Our observation that $24 \%$ of male survivors but $48 \%$ of female survivors decreased their working hours may reflect that women value work less than men, perhaps because of family commitments or of not being the main earner, as discussed in a growing body of literature concerning changes in the values of cancer survivors (Yabroff et al, 2004)

Our finding that nonworking was associated with a number of comorbidities in the general population but not in cancer survivors has been reported in two previous studies (Bradley et al, 2002b). For cancer survivors, deciding whether to work is associated with their cancer rather than their other morbidities (Bradley et al, 2002b).

Our finding that nonworking was significantly greater among those who received total gastrectomy than among those who received subtotal gastrectomy may be due to the side effects of the surgery, such as eating restrictions and weight loss, which may have negative effects on getting along in the workplace (Vickery et al, 2001; Bae et al, 2006). The fact that the type of surgery can affect a patient's ability to work after recovery should be considered in treatment decisions.

We found that physical limitation is the main correlate of not working and it may be caused by the fact that ECOG performance status was highly correlated with physical functioning (Kobayashi et al, 1998).

This study had several limitations. First, it may have been subject to selection bias, but to the extent that we could verify it, there seemed to be no systematic differences between participants and those we intended to recruit. Because the study sample was drawn from two hospitals while the control sample was drawn from 15 geographic districts, the health care market might be different for each group. However, the study sample from the two hospitals was distributed all across the country. In a complementary analysis, the distribution of districts in both samples was not different $(P=0.22$, data not shown). Additionally, we corrected for the different distribution of socio-demographic characteristics between the two groups by propensity score adjustment. That allowed for better control than was evident in studies that matched groups for only a few characteristics, such as age and education. Second, we used different recruiting methods for the two groups, but the eligibility requirements and self-reported questionnaire were the same for both. Third, the response rate of the general population $(41 \%)$ and the survivors $(59 \%)$ was relatively low. Because the reasons for refusal in both groups were unrelated to health problems or employment status, the fact that respondents differed from nonrespondents in having a greater male-to-female ratio, younger age, and a greater proportion of patients with earlystage disease was not likely to affect our results. Moreover, the low response rate was not likely to have influenced the findings in terms of working status because the employment rate of both the cancer survivors $(66.2 \%)$ and the general population sample $(63.5 \%)$ was similar to the employment rate of the Korean population $(63 \%)$ during the time of the study (Korea Statistical Information System, 2005).

We found that stomach cancer survivors had difficulties at work: due to increased fatigue and reduced capacity, and that the type of surgery received appeared to play a role. We believe that our findings will help stomach cancer patients make more realistic postsurgical employment plans. In addition, the information can inform occupational rehabilitation programmes, occupational health services, and employers and guide government policy for stomach cancer survivors.

\section{ACKNOWLEDGEMENTS}

This work was supported by National Cancer Center Grant 04101502 .

\section{Potential financial conflicts of interest}

None disclosed.

\section{REFERENCES}

Bae JM, Kim S, Kim YW, Ryu KW, Lee JH, Noh JH, Sohn TS, Hong SK, Park SM, You CH, Kim JH, Lee MK, Yun YH (2006) Health-related quality of life among disease-free stomach cancer survivors in Korea. Qual Life Res 15: $1587-1596$

Bednarek HL, Bradley CJ (2005) Work and retirement after cancer diagnosis. Res Nurs Health 28: 126-135

Stewart BW, Kleihues P (2003) World cancer report. International Agency for Research on Cancer. Lyon: IARC Press

Bradley CJ, Bednarek HL (2002a) Employment patterns of long-term cancer survivors. Psychooncology 11: 188-198

Bradley CJ, Neumark D, Luo Z, Bednarek H, Schenk M (2005) Employment outcomes of men treated for prostate cancer. J Natl Cancer Inst 97: 948-949
Bradley CJ, Bednarek HL, Neumark D (2002b) Breast cancer and women's labor supply. Health Serv Res 37: 1309-1328

Bouknight RR, Bradley CJ, Luo Z (2006) Correlates of return to work for breast cancer survivors. J Clin Oncol 24: $345-353$

Collins LG, Nash R, Round T, Newman B (2004) Perceptions of upper-body problems during recovery from breast cancer treatment. Support Care Cancer 12: $106-113$

Drolet M, Maunsell E, Brisson J, Brisson C, Masse B, Deschenes L (2005) Not working 3 years after breast cancer: predictors in a population-based study. J Clin Oncol 20: 8305-8312

Hewitt M, Rowland JH, Yancik R (2003) Cancer survivors in the United States: age, health, and disability. J Gerontol A Biol Sci Med Sci 58: 82 -91 
Kobayashi K, Takeda F, Teramukai S, Gotoh I, Sakai H, Yoneda S, Noguchi Y, Ogasawara H, Yoshida K (1998) A cross-validation of the European Organization for Research and Treatment of Cancer QLQ-C30 (EORTC QLQ-C30) for Japanese with lung cancer. Eur J Cancer 34: 810-815

Korea Statistical Information System (2005) Korea national statistics subcategory of employment, labor, and wages. http://kosis.nso.go.kr/ oracms/KOSIS/jtree/tree2.html

Lash TL, Silliman RA (2000) Patient characteristics and treatments associated with a decline in upper body function following breast cancer therapy. J Clin Epidemiol 53: 615-622

Levy PS, Lemeshow S (1991) Sampling of populations: methods and applications. New York: John Wiley pp 420

Maunsell E, Drolet M, Brisson J, Brisson C, Masse B, Deschenes L (2004) Work situation after breast cancer: results from a Population-Based Study. J Natl Cancer Inst 96: 1813-1822

Rosenbaum PR, Rubin DB (1983) The central role of the propensity score in observational studies for causal effects. Biometrika 70: 41-55

Roukos DH (1999) Current advances and changes in treatment strategy may improve survival and quality of life in patients with potentially curable gastric cancer. Ann Surg Oncol 6: 46-56

Serin D, Dilhuydy JM, Guiochet N, Romestaing P, Gledhill J, Bret P, Savary J, Flinois A (2005) Parcours de femmes 2001, a French survey on the management and needs of women with breast and gynecological cancer: what's new after 8 years? Bull Cancer 92: 817-827
Short PF, Vasey JJ, Tunceli K (2005) Employment pathways in a large cohort of adult cancer survivors. Cancer 103: 1292-1301

Stewart DE, Cheung AM, Duff S, Wong F, McQuestion M, Cheng T, Purdy L, Bunston T (2001) Long-term breast cancer survivors: confidentiality, disclosure, effects on work and insurance. Psychooncology 10: 259-263

Spelten ER, Verbeek JH, Uitterhoeve AL, Ansink AC, van der Lelie J, de Reijke TM, Kammeijer M, de Haes JC, Sprangers MA (2003) Cancer, fatigue and the return of patients to work-a prospective cohort study. Eur J Cancer 39: $1562-1567$

Vickery CW, Blazeby JM, Conroy T, Arraras J, Sezer O, Koller M, Rosemeyer D, Johnson CD, Alderson D, EORTC Quality of Life Group (2001) Development of an EORTC disease-specific quality of life module for use in patients with gastric cancer. Eur J Cancer 37: 966-971

Yabroff KR, Lawrence WF, Clauser S, Davis WW, Brown ML (2004) Burden of illness in cancer survivors: findings from a population-based national sample. J Natl Cancer Inst 96: 1322 - 1330

Yun YH, Kim SH, Lee KM, Park SM, Kim YM (2007) Age, sex, and comorbidities were considered in comparing reference data for healthrelated quality of life in the general and cancer populations. J Clin Epidemiol 60: $1164-1175$

Zakowski SG, Harris C, Krueger N, Laubmeier KK, Garrett S, Flanigan R, Johnson P (2003) Social barriers to emotional expression and their relations to distress in male and female cancer patients. $\mathrm{Br} J$ Health Psychol 8: 271-286 